Research Article

\title{
Constructing a Risk-Sharing Framework for Sponge City PPP Projects from the Perspective of the Individual Participant
}

\author{
Hui Zhao $\mathbb{D}$, Shengbin Ma, and Zehui Bu \\ School of Management Engineering, Qingdao University of Technology, Qingdao 266520, China \\ Correspondence should be addressed to Hui Zhao; zhaohui43@126.com
}

Received 7 July 2020; Revised 5 September 2020; Accepted 15 September 2020; Published 5 November 2020

Academic Editor: Yi Zhang

Copyright (c) 2020 Hui Zhao et al. This is an open access article distributed under the Creative Commons Attribution License, which permits unrestricted use, distribution, and reproduction in any medium, provided the original work is properly cited.

\begin{abstract}
Construction of sponge city PPP projects is perceived as a feasible measure for achieving the sustainable urbanization. To ensure the success of sponge city PPP projects, reasonable sharing of risks among participants, which has remained scarce and unscientific, is becoming an urgent problem to be solved. In order to enable the individual participant to accurately grasp the situation of his own risks, specifically for the individual participant, this paper constructs a risk-sharing framework for sponge city PPP projects. Firstly, this paper identifies critical risk factors by the Delphi method. The final risk evaluation index system is established from the perspectives of political risks, economic risks, construction risks, and operational risks, which include 16 secondary risk factors. Then, risk factors' weights are determined based on a combination weight method (combining the G1 method and the C-OWA operator). Next, in order to share risks reasonably, the first step is to obtain the risk factors that can be borne by one participant and define the risk factors that need to be shared among participants through the method of combining GCA method and TOPSIS method. The second step is to build a model based on the utility theory to determine the proportion of risks shared among participants. Finally, the sponge city PPP project in Qingshan demonstration area of Wuhan city as an example is employed to verify the feasibility and effectiveness of the constructed risk-sharing framework. All the aforementioned studies are expected to provide helpful references for reasonable risk sharing in sponge city PPP projects.
\end{abstract}

\section{Introduction}

The effective management of water resources is an important aspect of urban sustainable development [1]. Problems related to urban water have aroused the concern of the scientific community around the world [2]. In recent years, due to the rapid urbanization and extreme weather phenomena, serious water problems have emerged in cities, including the deterioration of natural ecology, poor permeability of surface water, severe urban flooding, water pollution degradation, insufficient water supply, and worsening water shortage [3]. For example, the construction of roofs, roads, and sites in cities and the resulting construction wastes change the original natural ecological environment and hydrological characteristics, which leads to the timely infiltration of rainwater to the ground and also presents a challenge to the sustainable development of the construction industry [4]. In addition, the traditional urban drainage system is difficult to adapt to the formation of storm runoff and flood peak, resulting in urban flood disaster [5]. Moreover, the traditional surface runoff method not only brings great pressure to the urban drainage system but also produces the urban nonpoint source water pollution [6]. Within this context, the idea of sponge city is put forward. As a healthy, green, and sustainable urban development model, sponge city strives to manage urban rainwater in a natural way on the premise of least affecting the urban water ecological environment by building a "sponge body" which is capable of water storage, water seepage, and water purification. However, sponge city projects are a project complex, including park project, sewage treatment plant project, water supply and drainage pipe network project, water ecology project, water environment renovation project, and other types of projects. These projects in the project complex are complicated in structure, involve many contents, and have high construction investment. 
Construction investment of the sponge city is about 29 million US dollars per square kilometer. The construction area of the sponge city is generally required to be no less than 15 square kilometers, and construction investment of each sponge city project is at least 435 million US dollars. It is obvious that it is difficult to meet the needs of urban development relying only on the financial investment of the local government in sponge city projects. The PPP (publicprivate partnership) model, namely, the public-private sector cooperation model, is based on the concession agreement and forms a partnership between each other, which enables two sectors to achieve more favorable results than expected by acting alone. In addition, in this model, the public sector is usually responsible for product pricing and supervision, while the design, construction, operation, and maintenance that need a large amount of capital investment are left to the private sector, which can effectively alleviate the financial pressure of the government. To address the challenges of urban water management and promote the successful implementation of sponge city projects, the model of "sponge city + PPP (public-private partnership)" has been highly praised by many scholars and vigorously implemented in the United States, Germany, Britain, and France. Especially in China, the number of sponge city PPP projects entering the project library of the China Public-Private Partnerships Center (CPPPC) has approximately soared to 200 during 2014-2019. The construction of sponge city PPP projects faces many technical innovations and challenges. Compared with traditional PPP projects, sponge city PPP projects have the recognizable characteristics of larger investment scale, more complicated subprojects, and more participants, which make the risks of sponge city PPP projects more complicated and special. One of the core ideas for the success of PPP projects is that the risks must be reasonably shared among participants. Regarding risk sharing of PPP projects, most scholars put forward some methods of risk sharing after establishing the risk evaluation system. After sorting out the research on risk sharing of existing PPP projects, it is found that the existing research has the following prominent problems: (1) in the existing PPP projects' risk research, participants are mostly divided into public sector and private sector. The results of risk sharing can only give a picture of public and private sector sharing. And those in the public or private sector have little control over their own risk-taking. (2) Although rich research results of PPP risk factors have been obtained, research on the risk evaluation index system of sponge city PPP projects is relatively limited. (3) Scholars have mostly studied risk-sharing methods by placing participants under a binary division (government and private sector), such as Delphi method [7, 8], game theory [9-11], and other methods. No matter whether the participants participate in the project alone or in the form of a consortium, in accordance with the core concept of PPP project operation (risks must be reasonably shared among participants), each participant should bear the corresponding risk. However, current research has not provided a scientific and reasonable method for the individual participants in the public and private sectors to accurately grasp the risks they should bear.
Therefore, to assure the success of sponge city PPP projects, how to realize rational risk sharing among participants is an urgent problem and very worthy of discussion. The present study can fill this research gap.

From the perspective of the individual participant, this paper constructs a risk-sharing framework for sponge city PPP projects, which could not only enable each participant to obtain the risk he should bear independently but also obtain the proportion of the risk they should share together, thus realizing reasonable risk sharing among participants. This paper makes the following practical and academic contributions. Firstly, aiming at the problem of the imperfect risk evaluation index system for sponge city PPP projects, we build a risk evaluation index system especially applicable to sponge city PPP projects through the Delphi method. Secondly, in view of the insufficiency of the current methods of determining the risk factors' weights in sponge city PPP projects, to be more scientific and reasonable, we propose a combination weight method that combines G1 method (order relation analysis method) and C-OWA (continuous ordered weighted average) operator, which lays a solid foundation for the next scientific risk sharing. Thirdly, in initial risk sharing, after comparison, we propose a more suitable risk-sharing method which combines GCA (grey correlation analysis) method and TOPSIS (technique for order preference by similarity to ideal solution) method. Finally, based on the utility theory, we break through the binary division (government and the private sector) and take four participants to jointly bear a certain risk as an example to discuss the problem of determining the proportion of a certain risk.

The remainder of this study is organized as follows. Section 2 presents the research status of sponge city PPP projects and risk sharing of PPP projects. In Section 3, we construct a risk-sharing framework, identify critical risk factors, determine weights of risk factors using the combination weight method, propose an approach combining the GCA method and TOPSIS method for initial risk sharing of sponge city PPP projects, and determine the proportion of shared risks based on utility theory. In Section 4, the feasibility and effectiveness of the constructed risk-sharing framework are verified by a case study. Finally, the conclusions and further work are presented in Section 5.

\section{Literature Review}

2.1. Sponge City PPP Projects. Sponge cities in developed countries are usually referred to as rainwater control systems. Germany has accumulated rich experience in the management of rainwater for low-impact development. The construction of sponge cities in Germany has been at the forefront of the world since the very beginning and has become a learning object for other countries. Countries such as Britain, the United States, and France also have rich experience in sponge city construction and creatively use the PPP model. Some scholars gave suggestions on applying the PPP model to sponge city projects. For example, based on the case of the sponge city PPP project in Prince George's County, Zhang [12] discussed the characteristics and key 
factors related to the PPP model, as well as the framework and key factors involved in the construction of the sponge city, including business scope, revenue source, delivery path, and private enterprise participation, and also introduced the application measures of the PPP model in the construction of the sponge city, which provided a reference for further promotion of the PPP model in the development of sponge city projects. After summarizing the advanced experience of sponge city construction projects and combining the social, economic, and political conditions in their own country, Kening et al. [13] constructed the chain of PPP investment mode from the perspective of investment and financing of sponge city projects and proposed the economic measures to attract social capital to actively participate in sponge city projects and the viewpoint to protect social capital, which laid a good foundation for promoting the construction of sponge city PPP projects. In developing countries, especially in China, to coordinate urbanization and sustainable development of environment and resources, China issued "several suggestions about strategic cooperation of sponge city construction special plan and PPP model" in 2015. PPP model was formally introduced into the construction of the sponge city. In order to promote the combination of the PPP model and sponge city projects, many scholars provided some countermeasures and suggestions. For example, based on the experience summary of the first sponge city construction pilot cities in China, Wang et al. [14] analyzed the investment and financing demand of sponge city construction, found out the problems such as insufficient participation of social capital in the model, and proposed the operation points of PPP financing in sponge city projects and the optimization suggestions of the project operation process. Li et al. [15] analyzed the feasibility of applying the PPP model in the sponge city project and the current situation of construction by combining the cases of the sponge city PPP project under construction in China and put forward relevant suggestions for further promoting the construction of sponge city PPP projects. Wang et al. [16] analyzed the problems existing in the construction of Chinese sponge city PPP projects, summarized and drew lessons from the relevant successful experience, and put forward the countermeasures and suggestions for the application of the PPP model in the sponge city. In general, sponge city PPP projects fit into the background of the current demand for ecological civilization and are a major direction of current and future government investment. The number of sponge city PPP projects will continue to rise rapidly.

2.2. Risk Sharing of PPP Projects. Risk sharing is one of the core concepts of "all-win" cooperation in PPP projects. In order to achieve the all-win goal, scholars have conducted extensive research. Most scholars have adopted the idea that the risk evaluation index system is constructed first, and then the sharing method is proposed. According to the expert experience, Lam et al. [17] firstly established seven risksharing criteria and a risk-sharing model based on the fuzzy reasoning rules. Then, they assessed each risk factor and made a decision plan for risk sharing. Finally, they used a practical case to explain the operation of the model. Tsang [18] adopted the Delphi method to construct a risk evaluation index system with 23 factors and then developed a fuzzy synthetic evaluation model for determining equitable risk sharing between the government and the private sector. Through the Delphi method, Chan et al. [8] pointed out that social capital was willing to take risks such as construction and operation risks, and the government was willing to take political, social, and legal risks, while environmental and other risks should be shared by both parties. Based on transaction cost theory and organizational capacity theory, Jin [19]constructed the PPP project risk evaluation index system and then used the fuzzy neural-network decision support system to evaluate and predict the reasonable risksharing strategy. Li and Ren [20] presented the main risks existing in PPP projects and proposed a new risk-sharing model based on Bayesian posterior probability to study how to share risks between the government and social capital. Using the Delphi method, Ameyaw and Chan [21] established a risk-sharing framework based on fuzzy set theory and concluded that risks should be shared between the government and the private sector, rather than transferred to one party. Considering risk sharing of PPP projects as a negotiation process, Medda [10] constructed a game model based on the final offer arbitration and analyzed the risksharing behaviors of the government and social capital under the premise of different goals. Li and Liu [22] used the utility theory to establish the benefit and cost utility functions of risk sharing between the government and the private sector and constructed the proportion model of project financing risk sharing between the government and the private sector under asymmetric negotiation status. They also verified the model through a case study. After establishing the risk-sharing evaluation system of sponge city PPP projects, Song and Chung [23] constructed the risk-sharing model of sponge city PPP projects based on AHP and TOPSIS methods and verified the rationality of the proposed method through a case study. Based on the risk preference analysis and bargaining game, Song and Chen [11] established a risk-sharing game model for the sewage treatment PPP project and obtained a risk-sharing scheme based on government departments, general contractors, and financial institutions. Finally, taking one complex project in A city as an example, they made an empirical analysis on the applicability of the risk-sharing model and put forward corresponding risk prevention suggestions. By summarizing the existing literature, it can be found that scholars have conducted in-depth studies on risk sharing of PPP projects. Some achievements have been made in the identification of key risk factors and methods of risk sharing. However, in terms of risk-sharing methods, most studies are based on the premise that the participants are binary, i.e., only divided into the government and the private sector. Even if a few scholars go beyond the binary division, such as Song and Chen, who proposed the tripartite game model and shared the risks among the three participants, they did not provide a scheme or method for sharing the total risk factors among all participants or main participants (larger than the three 
participants). These make it difficult to apply the existing sharing methods to the situations where all participants or main participants (larger than the three participants) shared risks. Moreover, in the identification of key risk factors of PPP projects, scholars have constructed different risk evaluation index systems according to different project types. However, in terms of the identification of key risk factors for sponge city PPP projects, the existing risk evaluation index system of sponge city PPP projects is still not imperfect and needs to be improved. Therefore, it is the focus of current and future research to build a perfect risk evaluation index system and study the risk-sharing method of sponge city PPP projects among all participants or main participants (larger than the three participants).

\section{Research Methodology}

3.1. Construct a Risk-Sharing Framework. There are many risks in the sponge city PPP project, some of which can be eradicated by certain technical measures, such as the adoption of insurance or guarantee, but there are also some risks that cannot be eliminated by technical measures. Therefore, these risks that cannot be eliminated must be shared to participants in sponge city PPP projects [24]. In order to ensure that each participant has access to its own risks accurately, it is necessary to consider the situation where a risk is borne by one participant or shared by both (or more) participants. Therefore, after establishing the risk evaluation index system of sponge city PPP projects, the main content of this paper is divided into two steps. The first step is initial sharing of risks to solve the risks that can be taken by one participant and define the risks that need to be shared. The second step is to determine the proportion of risks shared by both or more participants. Based on the above research ideas, the constructed risk-sharing framework of this study is arranged as shown in Figure 1.

\subsection{Establish a Risk Evaluation Index System of Sponge City} PPP Projects. In order to share the risks of sponge city PPP projects, an evaluation index system should be established. At present, the risk evaluation index system of PPP projects is mainly realized through the brainstorm method, Delphi method, scenario analysis method, check table method, flowchart method, SWOT method, and WBS method $[25,26]$. Considering that there are already many sponge city PPP projects, it is not difficult to gather experts, scholars, and practitioners in the field of sponge city PPP projects. Therefore, Delphi method is adopted to establish the risk evaluation index system of sponge city PPP projects in this paper. In view of the fact that there are many sponge city PPP projects and also many researchers and practitioners in China, the following three levels are considered: (1) experts should be managers with rich practical experience. They have at least 5 years of practical experience in sponge city PPP projects. Such experts can be mainly chosen from the participants of the sponge city PPP projects. (2) Experts should have rich theoretical knowledge of sponge city PPP projects. Moreover, these experts actively participate in sponge city PPP project training for government agencies and private sectors. These experts can be selected mainly from famous universities. (3) Efficiency: how many experts are appropriate? Some similar literature, such as [16], set the number of experts at 10 . This paper selects 10 Chinese experts (Table 1) in the Delphi method. According to the requirements of comprehensiveness, comparability, systematicness, and scientificity, the risks of sponge city PPP projects are divided into 4 first-level factors and 16 secondlevel factors by AHP (analytic hierarchy process). The process and results of determining key risk factors for sponge city PPP projects are shown in Figure 2 and Table 2.

3.3. Determine the Weight of Each Critical Risk Factor with the Combination Weight Method. The degree of influence of each risk factor in sponge city PPP projects is different. In order to realize reasonable risk sharing, this difference should be fully considered in the risk-sharing method. Therefore, prior to the calculation of specific risk sharing, after determining the risk evaluation index system of sponge city PPP projects, it is necessary to use appropriate methods to determine the specific weight of each index. In the multiindex decision-making problem, the determination of the weight directly affects the accuracy of risk sharing [23]. Although the subjective weighting method can reflect the attention degree of relevant experts to various factors, subjective weight methods depend too much on expert opinions, which are limited by personal knowledge and have certain limitations. Objective weighting can effectively utilize the nature of the data itself; however, objective weight methods rely on statistical and mathematical methods and ignore the human factors in the decision-making process, which makes it not close to the reality. Based on the shortcomings of subjective and objective weight methods, some scholars propose the combination weight method. At present, combination weight method is becoming a trend $[37,38]$. In this paper, the combination weight method (combining the G1 method and the C-OWA operator) is used to determine the weight of each risk evaluation index. Compared with the AHP method, G1 method, as a subjective weight method, does not need to construct a judgment matrix or conduct consistency test. The calculation is more concise and can better reflect the subjective preference of experts. However, this kind of weight method, which relies on the subjective scoring of experts, tends to produce extreme values and cannot reflect the change of objective conditions. However, the C-OWA operator can regroup the decision data through the combination number, assign the extreme data to the location with less influence, and assign the objective data to the location with greater influence. It can integrate and assign weight to each index, which greatly weakens the influence of the extreme value that may be generated by the subjective scoring and makes weighting more in line with the objective reality. Therefore, the combination of the two methods avoids the subjective and objective deviation caused by the single method so that the evaluation process is more scientific and reasonable. 


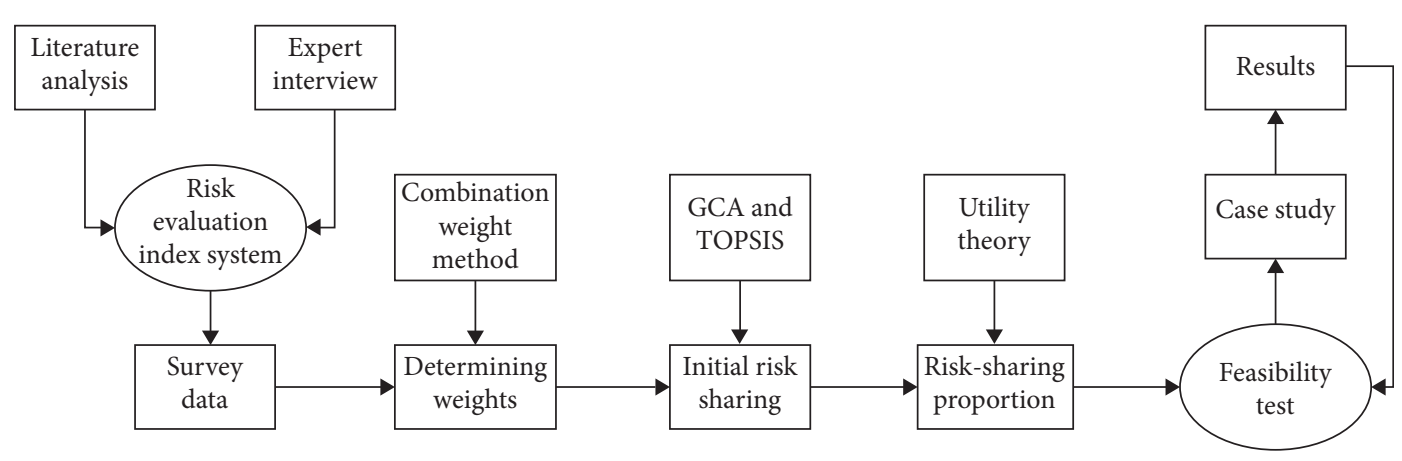

FIgURE 1: The constructed risk-sharing framework of this study.

TABLE 1: Information of the experts.

\begin{tabular}{lcc}
\hline No. & Work unit & Position \\
\hline 1 & Tsinghua University & Professor \\
2 & Tianjin University & Professor \\
3 & Qingdao Engineering Consulting Institute & Professional advisor \\
4 & Beijing Urban Construction Group & Chief engineer \\
5 & Qingdao City Financing Department & Official \\
6 & China Construction Eighth Engineering Division Co., Ltd & General manager \\
7 & Zhong Yin Law Firm & Lawyer \\
8 & Guangzhou International Engineering Consulting Corporation & Professional advisor \\
9 & Chongqing University & Professor \\
10 & Beijing City Financing Department & Official \\
\hline
\end{tabular}

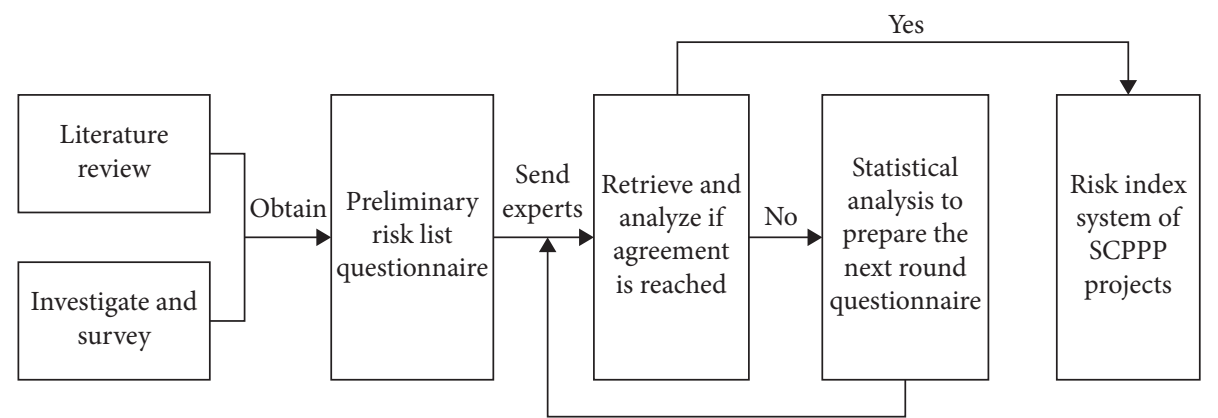

FIgURE 2: The process of determining risk factors of sponge city PPP projects.

3.3.1. Subjective Weights Based on the G1 Method. G1 method is an improved subjective weight method proposed by Professor Guo Yajun on the theoretical basis of analytic hierarchy process (AHP) [19]. G1 method mainly refers to a factor preference method that first sorts the importance of the measurement factors according to the expert opinions, then compares and judges the adjacent measurement factors one by one, and finally quantitatively assigns values on this basis. It can fully reflect the subjective opinions of experts, and its order of importance will not change with the change of factors. Therefore, this paper adopts the G1 method to achieve the subjective weights of risk factors, and the specific steps are as follows (Table 3):

Step 1: rank the risks in accordance with their importance. For the risk factor set $\left(c_{1}, c_{2}, \ldots, c_{n}\right)$, the unique ordering relationship can be obtained.
Step 2: determine the relative importance. $r_{i}=\omega_{i-1} / \omega_{i}$ of adjacent risk factors $c_{i-1}$ and $c_{i}$ according to Table 3 [10].

Step 3: calculate the subjective weights of risk factors by equations (1) and (2):

$$
\begin{aligned}
\omega_{i} & =\left(1+\sum_{i=2}^{n} \prod_{i}^{n} r_{i}\right), \\
\omega_{i-1} & =\omega_{i} * r_{i} .
\end{aligned}
$$

Considering the experts in Table 2 owning the voting right, the final weights were determined by the calculation result and $p$ decision makers' weights according to the following equation: 
TABLE 2: Risk evaluation index system of sponge city PPP projects.

\begin{tabular}{|c|c|c|}
\hline $\begin{array}{l}\text { First-level risk } \\
\text { factors }\end{array}$ & Second-level risk factors & Descriptions \\
\hline \multirow{4}{*}{$B_{1}$ political risks } & $c_{1}$ government intervention & $\begin{array}{l}\text { The term "government intervention" refers to the unreasonable intervention of } \\
\text { government officials in the construction and operation of a project, which affects the } \\
\text { decision of the project company [27]. }\end{array}$ \\
\hline & $c_{2}$ government default & $\begin{array}{l}\text { The term "government default" refers to the risk that the government violates credit } \\
\text { standards by not fulfilling its contractual obligations [16]. }\end{array}$ \\
\hline & $\begin{array}{l}c_{3} \text { immature law and } \\
\text { regulations }\end{array}$ & $\begin{array}{l}\text { The term "immature law and regulations" refers to the risk arising from incomplete } \\
\text { legal documents, conflicts between projects, poor operability, etc. [28]. }\end{array}$ \\
\hline & $c_{4}$ government inaction & $\begin{array}{l}\text { The term "government inaction" refers to some procedures that require government } \\
\text { coordination and approval in the construction of a project, while government } \\
\text { departments slack off [29]. }\end{array}$ \\
\hline \multirow{3}{*}{$B_{2}$ economic risks } & $c_{5}$ project financing failure & $\begin{array}{l}\text { This term "project financing failure" refers to the failure of project financing due to } \\
\text { the unreasonable financing structure and manner of the project company [30]. }\end{array}$ \\
\hline & $c_{6}$ interest rate & $\begin{array}{c}\text { The term "interest rate" refers to changes in project costs caused by fluctuations in } \\
\text { market interest rates [30]. }\end{array}$ \\
\hline & $c_{7}$ market price change & $\begin{array}{c}\text { The term "market price change" refers to changes in project costs caused by } \\
\text { fluctuations in market interest rates [31]. }\end{array}$ \\
\hline \multirow{5}{*}{$\begin{array}{l}B_{3} \text { construction } \\
\text { risks }\end{array}$} & $c_{8}$ cost overspending & $\begin{array}{l}\text { This term "cost overspending" refers to the cost increase caused by poor management } \\
\text { of the project company [32]. }\end{array}$ \\
\hline & $c_{9}$ time delay & The term "time delay" refers to delays caused by inefficient construction [28]. \\
\hline & $c_{10}$ lack of technical ability & $\begin{array}{l}\text { This term "lack of technical ability" refers to the project company's hiring of a } \\
\text { construction company whose technology is not up to par [33]. }\end{array}$ \\
\hline & $c_{11}$ change due to poor design & $\begin{array}{l}\text { This term "change due to poor design" refers to the design organization's poor } \\
\text { consideration of certain aspects of the design, resulting in change issues that affect the } \\
\text { cost and duration of the project [34]. }\end{array}$ \\
\hline & $c_{12}$ force majeure & $\begin{array}{c}\text { This term "force majeure" refers to events (geological conditions, bad weather, etc.) } \\
\text { that participants fail to anticipate or resist [35]. }\end{array}$ \\
\hline \multirow{3}{*}{$B_{4}$ operation risks } & $\begin{array}{l}c_{13} \text { lack of management } \\
\text { experience } \\
c_{14} \text { insufficient operating } \\
\text { income }\end{array}$ & $\begin{array}{l}\text { This term "lack of management experience" refers to the risk that the management is } \\
\text { not in place due to the operator's lack of management experience [16]. } \\
\text { The term "insufficient operating income" refers to the risk that operating income is } \\
\text { insufficient to meet expected profit levels [35]. }\end{array}$ \\
\hline & $\begin{array}{l}c_{15} \text { lack of an effective payment } \\
\text { mechanism }\end{array}$ & $\begin{array}{l}\text { The term "lack of an effective payment mechanism" refers to the fact that the current } \\
\text { income mainly depends on the government's purchase of services, while the new } \\
\text { income model is still under exploration, and it is difficult to guarantee the income of } \\
\text { social capital [28]. }\end{array}$ \\
\hline & $\begin{array}{l}c_{16} \text { unreasonable operating } \\
\text { technology }\end{array}$ & $\begin{array}{l}\text { This term "unreasonable operating technology" refers to the technology used in the } \\
\text { operation of the project company that does not conform to the current standard and } \\
\text { thus affects the operation effect [36]. }\end{array}$ \\
\hline
\end{tabular}

TABLE 3: The value of relative importance of criteria.

\begin{tabular}{lc}
\hline$r_{i}$ & Description \\
\hline 1.0 & $c_{i-1}$ has the same importance as $c_{i}$ \\
1.2 & $c_{i-1}$ is slightly more important than $c_{i}$ \\
1.4 & $c_{i-1}$ is more important than $c_{i}$ \\
1.6 & $c_{i-1}$ is strongly more important than $c_{i}$ \\
1.8 & $c_{i-1}$ is extremely more important than $c_{i}$ \\
\hline
\end{tabular}

$$
\omega_{i}^{\prime}=\frac{\omega_{1 i}+\omega_{2 i}+\cdots+\omega_{p i}}{p} .
$$

\subsubsection{Objective Weights Using the C-OWA Operator.} OWA operator theory was first proposed by Professor Yager [39]. On this basis, many scholars have carried out in-depth improvement research and proposed many different types of OWA operators. At present, the C-OWA operator has been widely used to determine the index weight [40]. The C-OWA operator is an ordered weighted average operator based on the combination number. The steps to empowerment are as follows:

Step 1: $p$ experts are invited to give scores according to the importance of the indicators at the same level ( $0-10$ scoring method) [40]. The initial scoring data set of each indicator given by $n$ experts is $Z=\left(Z_{1}, Z_{2}, \ldots, Z_{j}, \ldots, Z_{n}\right)$. Then, the scoring data are sorted from large to small and numbered from 0 . The result $z_{0} \geq z_{1} \geq, \ldots, \geq z_{j} \geq, \ldots, \geq z_{n-1}$ is obtained. So, new data set $b_{j}=\left(b_{0}, b_{1}, \ldots, b_{n-1}\right)$.

Step 2: determine the weight $\theta_{j+1}$ of data $z_{i}$ directly by the combinatorial number $C_{n-1}^{j}$, where $\sum_{j=0}^{n-1} \theta_{j+1}=1$, namely,

$$
\theta_{j+1}=\frac{C_{n-1}^{j}}{\sum_{k=0}^{n-1} C_{n-1}^{k}}=\frac{C_{n-1}^{j}}{2^{n-1}}, \quad j=0,1, \ldots, n-1 .
$$


Step 3: weigh the initial decision data set $Z$ successively by weight $\theta_{j+1}$, and calculate the absolute weight $\bar{\omega}_{i}$ of the index by the following equation:

$$
\bar{\omega}_{i}=\sum_{j=0}^{n-1} \theta_{j+1} b_{j}, \quad i=1,2, \ldots, m,
$$

where $m$ represents the number of indicators.

Step 4: calculate the relative weight value $\bar{\omega}_{i}$ of index $C_{i}$ by the following equation:

$$
\omega_{i}^{\prime \prime}=\frac{\bar{\omega}_{i}}{\sum_{i=1}^{m} \omega_{i}}, \quad i=1,2, \ldots, m .
$$

3.3.3. Determine the Combination Weight on the Basis of Lagrange Theory. Combining the G1 method with the C-OWA operator, the combination weight method integrates professional opinions of experts in the G1 method and uses the entropy objective weight method to avoid subjective errors, which makes the final risk factors' weights more scientific and reasonable. Under the condition that $\omega_{j}^{\prime \prime}$ and $\omega_{j}^{\prime \prime}$ are known, this paper builds an optimization model based on the Lagrange theory to achieve the combination weights of risk factors. The combination weight model is shown in the following equation:

$$
\omega_{i}=v_{1} \omega_{i}^{\prime}+v_{2} \omega_{i}^{\prime \prime}
$$

where $v_{1}$ and $v_{2}$ are the undetermined coefficients, $i=1,2, \cdots$, $m$ and $v_{1}, v_{2} \geq 0, v_{1}+v_{2}=1$. Moreover, the undetermined coefficients $v_{1}$ and $v_{2}$ can be transformed into the following optimization problem:

$$
\left\{\begin{array}{l}
\max F\left(v_{1}, v_{2}\right)=\sum_{i=1}^{m}\left(\sum_{j=1}^{n}\left(v_{1} \omega_{i}^{\prime}+v_{2} \omega_{i}^{\prime \prime}\right)\right), \\
v_{1}+v_{2}=1, \quad v_{1}, v_{2} \geq 0 .
\end{array}\right.
$$

Furthermore, according to the extreme value condition of Lagrange, $v_{1}$ and $v_{2}$ can be achieved using Lagrange functions, which are shown in equations (9) and (10):

$$
\begin{aligned}
& \left\{\begin{array}{l}
v_{1}^{\prime}=\frac{\sum_{i=1}^{m} \sum_{j=1}^{n} \omega_{i}^{\prime} x_{i j}}{\sqrt{\left(\sum_{i=1}^{m} \sum_{j=1}^{n} \omega_{i}^{\prime} x_{i j}\right)^{2}+\left(\sum_{i=1}^{m} \sum_{j=1}^{n} \omega_{i}^{\prime \prime} x_{i j}\right)}} \\
v_{2}^{\prime}=\frac{\sum_{i=1}^{m} \sum_{j=1}^{n} \omega_{i}^{\prime \prime} x_{i j}}{\sqrt{\left(\sum_{i=1}^{m} \sum_{j=1}^{n} \omega_{i}^{\prime} x_{i j}\right)^{2}+\left(\sum_{i=1}^{m} \sum_{j=1}^{n} \omega_{i}^{\prime \prime} x_{i j}\right)}} . \\
v_{1}=\frac{v_{1}^{\prime}}{\left(v_{1}^{\prime}+v_{2}^{\prime}\right)}, \\
v_{2}=\frac{v_{2}^{\prime}}{\left(v_{1}^{\prime}+v_{2}^{\prime}\right)} .
\end{array}\right.
\end{aligned}
$$

3.4. Realize Initial Risk Sharing of Sponge City PPP Projects. In order to ensure that each participant accurately obtains his own risks, it is necessary to consider the situation in which a risk is borne by one participant or shared by both (or more) participants. To this end, it is also necessary to research in two steps. The first step is initial sharing of risks, solving the risks that can be borne by one participant and defining the risks that need to be shared. The second step is to determine the proportion of risks shared by two or more participants.

3.4.1. Selection of the Initial Risk-Sharing Method. In terms of the principle of risk sharing, scholars have reached a broad consensus that risk sharing is not simply equal sharing but should be shared to the most suitable participant to bear the risk. Based on this principle, a few scholars use the GCA method to study risk sharing. The grey relational degree reflects the approximate order of each evaluation object and the ideal solution. The more similar the shape of the two curves, the greater the correlation between the two sequences. However, most of the previous studies fail to consider the correlation between the evaluation object and the negative ideal solution, which leads to one-sidedness of the evaluation results. By setting the ideal solution and negative ideal solution, TOPSIS method, which is based on the criteria of approaching the ideal solution and staying away from the negative ideal solution, is a kind of sorting method to approximate the ideal solution. However, taking the degree of proximity as a measurement standard can only show the position relationship between curves but cannot reflect the future development trend of data series. In the case of large difference in index values, as long as the distance between the evaluation object and the ideal solution is similar, similar results will still be obtained. For these reasons, GCA method and TOPSIS method, respectively, reflect the closeness of the evaluation object to the ideal solution from the shape similarity and position and, at the same time, reflect the characteristics of double benchmarks. This paper organically combines these two methods to learn from each other and apply them to the initial risk sharing of sponge city PPP projects.

3.4.2. Realize Initial Risk Sharing. The grey relational degree is judged by the similarity degree of curve fitting. For a multiindex evaluation, if the correlation degree between a certain evaluation object and the ideal solution set by the system is larger, it can be considered that the evaluation object is closer to the ideal solution. On the contrary, if the correlation degree with the negative ideal solution is greater, the similarity degree between the evaluation object and the negative ideal solution is higher. Therefore, the relative closeness degree can be constructed after the correlation degree between the evaluation object and the ideal solution and the grey correlation degree between the evaluation object and the negative ideal solution are calculated to realize initial risk sharing. The specific calculation steps are as follows: 
Step 1: the weight vector $\omega_{i}$ calculated by the combination weight method is multiplied by the normalized matrix $F\left(F=\left(y_{i j}\right)\right.$ number of evaluation objects $\times$ number of evaluation indicators) to obtain the weighted normalized matrix $Z$, as shown in the following equation.

$$
Z=\left(z_{i j}\right)_{t x z}=\left(\omega_{i} y_{i j}\right)_{t x z} \text {. }
$$

Step 2: positive ideal solutions $z_{j}^{+}$and negative ideal solutions $z_{j}^{-}$of the object to be evaluated are determined by equations (12) and (13):

$z_{j}^{+}=\left\{\max _{i} z_{i j}\left|z_{i j} \in Z^{+}, \min _{i} z_{\mathrm{ij}}\right| z_{i j} \in Z^{-}\right\}=\left\{z_{1}^{+}, z_{2}^{+}, \ldots, z_{z}^{+}\right\}$,

$z_{j}^{-}=\left\{\max _{i} z_{i j}\left|z_{i j} \in Z^{+}, \max _{i} z_{i j}\right| z_{i j} \in Z^{-}\right\}=\left\{z_{1}^{-}, z_{2}^{-}, \ldots, z_{z}^{-}\right\}$.

Among them, the larger $z_{1}^{+}$is, the better the index is, while the smaller $z_{1}^{-}$is, the better the index is.

Step 3: for the $j$ th index, calculate the grey relational degree $\xi_{i j}^{+}$between the $i$ th evaluation object and the positive ideal solution and the grey relational degree $\xi_{\mathrm{ij}}^{-}$between the $i$ th evaluation object and the negative ideal solution, as shown in equations (14) and (15).

$$
\xi_{i j}^{+}=\left(\frac{1}{z}\right) \sum_{j=1}^{z} \frac{\min _{i} \min _{j}\left|z_{i j}-z_{j}^{+}\right|+\rho \max _{i} \max _{j}\left|z_{i j}-z_{j}^{+}\right|}{\left|z_{i j}-z_{j}^{+}\right|+\rho \max _{i} \max _{j}\left|z_{i j}-z_{j}^{+}\right|},
$$

$$
\xi_{i j}^{-}=\left(\frac{1}{z}\right) \sum_{j=1}^{z} \frac{\min _{i} \min _{j}\left|z_{i j}-z_{j}^{-}\right|+\rho \max _{i} \max _{j}\left|z_{i j}-z_{j}^{-}\right|}{\left|z_{i j}-z_{j}^{-}\right|+\rho \max _{i} \max _{j}\left|z_{i j}-z_{j}^{-}\right|},
$$

where $\rho$ is the resolution coefficient, and its general value is 0.5 .

Step 4: calculate the grey correlation $\gamma_{i}^{+}$between the $i$ th evaluation object and $z_{j}^{+}$and the grey correlation $\gamma_{i}^{-}$ between $i$ th evaluation object and $z_{j}^{-}$by equations (16) and (17).

$$
\begin{aligned}
& \gamma_{i}^{+}=\sum_{j=1}^{n} w_{j} \xi_{i j}^{+}, \\
& \gamma_{i}^{-}=\sum_{j=1}^{n} w_{j} \xi_{i j}^{-} .
\end{aligned}
$$

Step 5: calculate the relative closeness value $R_{i}$ of the evaluation object to $z_{j}^{+}$and $z_{j}^{-}$by the following equation:

$$
R_{i}=\frac{\gamma_{i}^{+}}{\gamma_{i}^{+}+\gamma_{i}^{-}}
$$

\subsection{Determine the Risk-Sharing Proportion of Sponge City PPP} Projects. After the initial risk share of sponge city PPP projects, each participant obtains the risk borne by himself and the risk shared with other participants. It is not enough to stipulate vaguely that the risks are shared by both (or more than two) participants. For the economic loss caused by the occurrence of risk events, how much each participant bears directly affects his income, as well as the selection and decision of specific compensation schemes.

\subsubsection{Determine the Proportion of Shared Risks Based on the} Utility Theory. As an economic man, the purpose of risk resharing is to maximize the utility of both participants (or more than two participants) in the project. In the utility theory, the impact of risk resharing on the project effect can be summarized as the project cost and benefit, so the effect of risk resharing depends on the achievement of the goal. The process of risk resharing emphasizes sharing of risks. As the risk-sharing proportion between both participants (or more than two participants) tends to be reasonable, the willingness of both participants (or more than two participants) to bear will keep increasing, the total project cost will keep decreasing, and the utility of the project will also keep increasing. When the risk-sharing proportion reaches a certain critical value, the willingness and control ability of both participants (or more than two participants) to bear risks will begin to weaken, which will bring the improvement of the total project cost and the reduction of management efficiency. Therefore, there is a reasonable risk-sharing proportion to make the sharing effect best (as shown in Figure 3).

Based on the utility theory, this paper breaks through the binary division and takes four participants to jointly bear a certain risk as an example to discuss the problem of determining the proportion of a certain risk among four participants (GD-government department, MP1-main participant 1, MP2-main participant 2, and MP3-main participant 3). From the view of the case investigation, this situation is already the limit, and for the case where three participants share the risk or two participants share the risk, the calculation can be completed by removing one or two participants, respectively, from the established utility theory model.

3.5.2. Logical Computation Process. Suppose that the utility function of the risk-sharing participants of sponge city PPP projects is expressed by the function of income $V$ and cost $C$, namely, $U=U(V, C)$. The main procedure is given as follows:

Step 1: in order to meet practical needs and achieve utility maximization and risk minimization, the established risk-sharing optimization model can be expressed as 


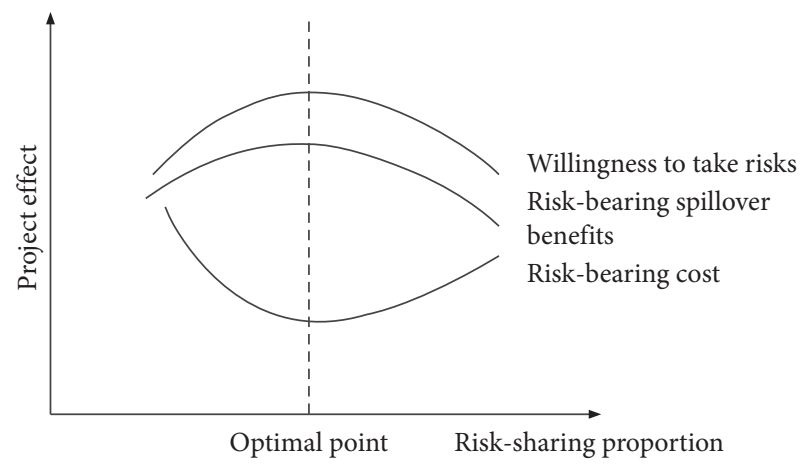

Figure 3: Effect of risk sharing.

$\left\{\begin{array}{l}\max \left(U_{1}\left(V_{1}, C_{1}\right)+U_{2}\left(V_{2}, C_{2}\right)+U_{3}\left(V_{3}, C_{3}\right)+U_{4}\left(V_{4}, C_{4}\right)\right), \\ \min C_{r}\left(C_{1}, C_{2}, C_{3}, C_{4}\right),\end{array}\right.$

where the utility functions, benefits, costs, and actual costs of the above participants are, respectively, represented by $U_{k}, V_{k}, C_{k}$, and $C_{r}$.

Step 2: assuming that the expected risk cost of sponge city PPP projects is $C_{e}$, the risk-sharing proportions of GD, MP1, and MP2 are $t_{1}, t_{2}$, and $t_{3}$, respectively, and then the risk-sharing proportion of MP3 is $1-t_{1}-t_{2}-t_{3}$. The cost of each risk-sharing participant can be expressed as

$$
\left\{\begin{array}{l}
C_{e}=C_{e 1}+C_{e 2}+C_{e 3}+C_{e 4}, \\
C_{r}=C_{r 1}+C_{r 2}+C_{r 3}+C_{r 4}, \\
C_{e 1}=t_{1} C_{e} ; C_{r 1}=t_{1} C_{r}, \\
C_{e 2}=t_{2} C_{e} ; C_{r 2}=t_{2} C_{r}, \\
C_{e 3}=t_{3} C_{e} ; C_{r 3}=t_{3} C_{r}, \\
C_{e 4}=\left(1-t_{1}-t_{2}-t_{3}\right) C_{e} ; C_{r 4}=\left(1-t_{1}-t_{2}-t_{3}\right) C_{r 3} .
\end{array}\right.
$$

Among them, $0 \leq_{t_{1}} \leq 1 ; \quad 0 \leq_{t_{2}} \leq 1 ;$ and $0 \leq_{t_{3}} \leq 1$. $C_{e k}$ and $C_{r k}$ are the expected and actual costs paid by GD, MP1, MP2, and MP3 in sponge city PPP projects, respectively, $k=1,2,3$, and 4 .

Step 3: the effectiveness functions of the actual cost of the risk of sponge city PPP projects can be expressed as follows:

$$
\left\{\begin{array}{l}
C_{r 1}=M\left(t_{1}, C_{e 1}\right), \\
C_{r 2}=O\left(t_{2}, C_{e 2}\right), \\
C_{r 3}=G\left(t_{3}, C_{e 3}\right), \\
C_{r 4}=A\left(t_{1}-t_{2}-t_{3}, C_{e 4}\right),
\end{array}\right.
$$

where $M, O, G$, and $A$ are the effectiveness functions of each risk-sharing participant, respectively.

Step 4: when the risk is effectively controlled by each participant, the probability of risk occurrence and loss will be reduced, the actual cost will be low, and some spillover benefits will be generated, namely,

$$
\left\{\begin{array}{l}
V_{1}=C_{e 1}-C_{r 1}=t_{1}\left(C_{e}-C_{r}\right), \\
V_{2}=C_{e 2}-C_{r 2}=t_{2}\left(C_{e}-C_{r}\right), \\
V_{3}=C_{e 3}-C_{r 3}=t_{3}\left(C_{e}-C_{r}\right), \\
V_{4}=C_{e 4}-C_{r 4}=\left(1-t_{1}-t_{2}-t_{3}\right)\left(C_{e}-C_{r}\right) .
\end{array}\right.
$$

Substituting equation (25) into equation (22), the following can be obtained:

$$
\left\{\begin{array}{l}
\max \left[U_{1}\left(t_{1}\left(C_{e}-C_{r}\right), t_{1} C_{r}\right)+U_{2}\left(t_{2}\left(C_{e}-C_{r}\right), t_{2} C_{r}\right)+U_{3}\left(t_{3}\left(C_{e}-C_{r}\right), t_{3} C_{r}\right)+U_{4}\left(\left(1-t_{1}-t_{2}-t_{3}\right)\left(C_{e}-C_{r}\right)\right.\right. \\
\left.\left.\quad\left(1-t_{1}-t_{2}-t_{3}\right) C_{r}\right)\right] \\
\min C_{r}
\end{array}\right.
$$

Step 5: as GD, MP1, MP2, and MP3 are often inconsistent in their discourse power when negotiating on risk sharing, which results in the failure of the utility functions of the four participants to reach the extreme value, a comprehensive utility function needs to be constructed, namely,

$$
\begin{aligned}
f\left(U_{1}, U_{2}, U_{3}, U_{4}\right)= & \beta_{1}\left(U_{1}-U_{1}^{\prime}\right)+\beta_{2}\left(U_{2}-U_{2}^{\prime}\right) \\
& +\beta_{3}\left(U_{3}-U_{3}^{\prime}+\beta_{4}\left(U_{4}-U_{4}^{\prime}\right)\right),
\end{aligned}
$$

where $\beta_{k}$ is the weight of the four participants in the project negotiation, $k=1,2,3$, and 4 , and $U_{k}^{\prime}$ is the 
initial utility value of the four participants unaffected by the risk.

Step 6: as there are many risks in the actual operation of the sponge city PPP project, it is difficult to estimate the total risk cost of the project. Therefore, it is assumed that the cost $\overline{E C}$ jointly hoped by GD, MP1, MP2, and MP3 is the lowest risk cost of the project, namely, $\min C_{r}=\overline{E C}$. Accordingly, it can be obtained that

$$
\begin{aligned}
\max f\left(U_{1}, U_{2}, U_{3}, U_{4}\right)= & \max \left\{\beta_{2}\left[U_{1}\left(t_{1}\left(C_{e}-C_{r}\right), t_{1} C_{r}\right)-U_{1}^{\prime}\right]+\beta_{2}\left[U_{2}\left(t_{2}\left(C_{e}-C_{r}\right), t_{2} C_{r}\right)-U_{2}^{\prime}\right]\right. \\
& +\beta_{3}\left[U_{3}\left(t_{3}\left(C_{e}-C_{r}\right), t_{3} C_{r}\right)-U_{3}^{\prime}\right]+\beta_{4}\left[U _ { 3 } \left(\left(1-t_{1}-t_{2}-t_{3}\right)\left(C_{e}-C_{r}\right),\right.\right. \\
& \left.\left.\left.+\left(1-t_{1}-t_{2}-t_{3}\right) C_{r}\right)-U_{4}^{\prime}\right]\right\}, \\
\text { s.t. } C_{r}= & \overline{E C} .
\end{aligned}
$$

Step 7: partial derivatives of $t_{1}, t_{2}$, and $t_{3}$ of GD, MP1, MP2, and MP3 in $f\left(U_{1}, U_{2}, U_{3}, U_{4}\right)$, where $C_{r}$ is a function of $t_{1}, t_{2}$, and $t_{3}$, and more $C_{e}$ is a constant. Then, the partial derivative with respect to $t_{1}$ is

$$
\begin{aligned}
\frac{\partial f}{\partial t_{1}}= & \beta_{1}\left[\left(C_{e}-C_{r}\right)\left(\frac{\partial U_{1}}{\partial V_{1}}\right)-t_{1}\left(\frac{\partial C_{r} \partial U_{1}}{\partial t_{1} \partial V_{1}}\right)+C_{r}\left(\frac{\partial U_{1}}{\partial C_{1}}\right)\right. \\
& \left.+t_{1}\left(\frac{\partial C_{r} \partial U_{1}}{\partial t_{1} \partial C_{1}}\right)\right]+\beta_{4}\left[\left(C_{r}-C_{e}\right)\left(\frac{\partial U_{4}}{\partial V_{4}}\right)\right. \\
& -\left(1-t_{1}-t_{2}-t_{3}\right)\left(\frac{\partial C_{r} \partial U_{4}}{\partial t_{1} \partial V_{4}}\right)-C_{r}\left(\frac{\partial U_{4}}{\partial C_{4}}\right) \\
& \left.+\left(1-t_{1}-t_{2}-t_{3}\right)\left(\frac{\partial C_{r} \partial U_{4}}{\partial t_{1} \partial C_{4}}\right)\right]=0 .
\end{aligned}
$$

Similarly, take the partial derivatives of $t_{2}$ and $t_{3}$ :

$$
\begin{aligned}
& \frac{\partial f}{\partial t_{2}}=0, \\
& \frac{\partial f}{\partial t_{3}}=0 .
\end{aligned}
$$

Step 8: in combination with equations (26) and (27), it can be known that the optimal risk-sharing proportions $t_{1}^{\prime}, t_{2}^{\prime}, t_{3}^{\prime}$ obtained are functions of the weight $\beta_{k}$ of each participant in the negotiation. Here, Lagrangian theorem is used to solve the optimal solution of equation (25). Suppose $t_{1}^{\prime}=\xi_{1}\left(\beta_{1}, \beta_{2}, \beta_{3}, \beta_{4}\right), t_{2}^{\prime}=\xi_{2}\left(\beta_{1}, \beta_{2}, \beta_{3}\right.$, $\left.\beta_{4}\right)$, and $t_{3}^{\prime}=\xi_{3}\left(\beta_{1}, \beta_{2}, \beta_{3}, \beta_{4}\right)$; then, we can get

$$
\begin{aligned}
L= & f\left(U_{1}, U_{2}, U_{3}, U_{4}\right)+\lambda\left(\overline{E C}-C_{r}\right) \\
= & \beta_{1}\left[U_{1}\left(t_{1}^{\prime}\left(C_{e}-C_{r}\right), t_{1}^{\prime} C_{r}\right)-U_{1}^{\prime}\right] \\
& +\beta_{2}\left[U_{2}\left(t_{2}^{\prime}\left(C_{e}-C_{r}\right), t_{2}^{\prime} C_{r}\right)-U_{2}^{\prime}\right] \\
& +\beta_{3}\left[U_{3}\left(t_{3}^{\prime}\left(C_{e}-C_{r}\right), t_{3}^{\prime} C_{r}\right)-U_{3}^{\prime}\right] \\
& +\left(1-\beta_{1}-\beta_{2}-\beta_{3}\right)\left[U_{4}\left(\left(1-t_{1}^{\prime}-t_{2}^{\prime}-t_{3}^{\prime}\right)\right)\right. \\
& \left.+\left(C_{e}-C_{r}\right),\left(\left(1-t_{1}^{\prime}-t_{2}^{\prime}-t_{3}^{\prime}\right) C_{r}\right)-U_{4}^{\prime}\right]+\lambda\left(\overline{E C}-C_{r}\right) .
\end{aligned}
$$

Make $(\partial L / \partial \lambda)=0,\left(\partial L / \partial \beta_{1}\right)=0,\left(\partial L / \partial \beta_{2}\right)=0$, and $\left(\partial L / \partial \beta_{3}\right)=0$; then, equation $(28)\left(\partial L / \partial \lambda=\overline{E C}-C_{r}=0\right)$ can be obtained.

Furthermore, we can get

$$
\left(\frac{\partial L}{\partial \beta_{1}}\right)=\left(\frac{\partial L}{\partial \beta_{2}}\right)=\left(\frac{\partial L}{\partial \beta_{1}}\right)=0 .
$$

Therefore, the actual cost $C_{r}$ can be calculated by using equation (25). At the same time, equations (26)-(29) can be used to calculate the weights $\beta_{k}$ of GD, MP1, MP2, and MP3 in the negotiation and the optimal risk-sharing proportion of the four participants, which realize the specific share proportion of four participants in the shared risk.

\section{Case Study}

By July 2020, there have been 30 pilot sponge cities in China, and PPP mode has been adopted in most sponge city projects in the construction process. Although there are differences in the scale, location, and complexity of these sponge city PPP projects, the operation logic relationship is basically the same. The sponge city PPP project of Qingshan demonstration area of Wuhan City is a very representative sponge City PPP project at present. For this reason, to verify the feasibility and effectiveness of the constructed risk-sharing framework for sponge city PPP projects, this paper takes the sponge city PPP project in Qingshan demonstration area of Wuhan city as an example to make an empirical study. In April 2015, Wuhan was selected as one of the first batch of sponge city construction pilot cities in China. The sponge city PPP project of Qingshan demonstration area is one of two demonstration cores of Wuhan sponge city construction. The sponge city PPP project of Wuhan Qingshan demonstration area starts from Industrial Road in the west and reaches Bingang Road in the east, Friendship Avenue in the south, and Heping Avenue in the north, with a total area of $3.84 \mathrm{~km}^{2}$, benefiting nearly 100,000 residents around. It involves 13 municipal roads, 59 community public construction projects, 2 parks and green space projects, 3 urban canal projects, and 1 urban water system project. The construction period of the project is 2 years, and the operation period is 8 years. The total investment budget of the project is about 1.27 billion yuan. The project capital is invested by the project company with its own capital, which 
accounts for $20 \%$ of the total investment, about 250 million yuan. The remaining 1.02 billion yuan is financed by the project company through financial institutions, accounting for about $80 \%$ of the total investment. The main participants are a government representative (Wuhan Sponge City Construction Co., Ltd.-WSCC), a private sector consortium (Wisco Green City Construction and Development Co., Ltd.-WGCCD, Wuhan Iron \& Steel Co., Ltd.-WIS, and Wisco City Service Co., Ltd.-WCS), and a financial institution (FI). The specific operation mode is shown in Figure 4.

According to the constructed risk-sharing framework for sponge city PPP projects, after establishing the risk evaluation index system, the main steps are divided into two phases. One phase is that initial risk sharing of sponge city PPP projects is realized by combining the GCA method and TOPSIS method. Another phase is that the proportion of shared risks is determined based on the utility theory.

4.1. Realize Initial Risk Sharing of Sponge City PPP Projects by Combining the GCA Method and TOPSIS Method. As shown

\begin{tabular}{|c|c|c|c|c|c|c|c|c|c|c|c|c|c|c|c|}
\hline 0.0052 & 0.0034 & 0.0030 & 0.0036 & 0.7073 & 0.6782 & 0.7920 & 0.8153 & 0.9130 & 0.9101 & 0.9125 & 0.6120 & 0.3132 & 0.6113 & 0.6116 & 0.2190 \\
\hline 0.0121 & 0.0053 & 0.0046 & 0.0033 & 0.7084 & 0.6121 & 0.7761 & 0.8146 & 0.9162 & 0.9291 & 0.9162 & 0.6163 & 0.3241 & 0.6160 & 0.6113 & 0.2111 \\
\hline 0.0101 & 0.0075 & 0.0037 & 0.0026 & 0.7078 & 0.6702 & 0.7011 & 0.8663 & 0.9100 & 0.9310 & 0.9103 & 0.6161 & 0.3320 & 0.6110 & 0.6135 & 0.2162 \\
\hline 0.0092 & 0.0051 & 0.0043 & 0.0028 & 0.7076 & 0.6131 & 0.7392 & 0.8701 & 0.9112 & 0.9261 & 0.9098 & 0.6190 & 0.3136 & 0.6152 & 0.6112 & 0.3190 \\
\hline 0.0104 & 0.0038 & 0.0035 & 0.0033 & 0.7487 & 0.6665 & 0.7212 & 0.8602 & 0.9120 & 0.9123 & 0.9141 & 0.6130 & 0.3151 & 0.6161 & 0.6133 & 0.3111 \\
\hline \multicolumn{16}{|l|}{$F=$} \\
\hline 0.0060 & 0.0062 & 0.0033 & 0.0032 & 0.7952 & 0.6462 & 0.7667 & 0.8521 & 0.9151 & 0.9361 & 0.9103 & 0.6161 & 0.3129 & 0.6123 & 0.6118 & 0.3165 \\
\hline 0.0063 & 0.0066 & 0.0041 & 0.0031 & 0.7576 & 0.6523 & 0.7397 & 0.8636 & 0.9093 & 0.9132 & 0.9142 & 0.6160 & 0.3182 & 0.6114 & 0.6154 & 0.2142 \\
\hline 0.0085 & 0.0052 & 0.0035 & 0.0036 & 0.7766 & 0.6312 & 0.7653 & 0.8442 & 0.9091 & 0.9110 & 0.9132 & 0.6110 & 0.3135 & 0.6101 & 0.6165 & 0.2140 \\
\hline 0.0076 & 0.0064 & 0.0038 & 0.0038 & 0.7583 & 0.6541 & 0.7246 & 0.8351 & 0.9106 & 0.9221 & 0.9102 & 0.6114 & 0.3156 & 0.6162 & 0.6111 & 0.2161 \\
\hline 0.0050 & 0.0053 & 0.0033 & 0.0036 & 0.7592 & 0.6064 & 0.7062 & 0.8670 & 0.9098 & 0.9130 & 0.9099 & 0.6123 & 0.3147 & 0.6103 & 0.6113 & 0.2123 \\
\hline
\end{tabular}

Step 2: determine weights of $C_{1} \sim C_{16}$ using the combination weight method.

Firstly, 10 experts in Table 2 endow each risk value according to the value of relative importance of criteria in Table 3 and the importance of the indexes at the same level (0-10 scoring method), respectively. Then, subjective weights are calculated based on the G1 method in Table 2, there are altogether 16 risk evaluation indexes of sponge city PPP projects, namely, $C_{1} \sim C_{16}$. According to the risk-sharing method proposed in this paper, it is intended to determine the risk factors that each participant should bear by calculating the relative closeness between each participant and these 16 risk evaluation indexes. Here, Wisco Green City Construction and Development Co., Ltd.-WGCCD (the same as other participants in the risk-sharing process) is selected as the demonstration object to demonstrate the risksharing process (Table 4).

Step 1: nondimensionalize original risk data. Based on their experience and knowledge, 10 experts in Table 2 firstly assign a value to each risk factor according to risk sensitivity in Table 4 [41]. Then, the original risk data matrix is obtained. Last, in order to achieve the unity of calculation, the obtained original data matrix should be nondimensionalized. For the sake of simple calculation, the range analysis [40] is adopted here. The nondimensionalized matrix can be expressed as F:

mentioned through equations (1)-(3), and objective weights are also obtained using the C-OWA operator by equations (4)-(6). Finally, combination weights are achieved by equations (7)-(10). Related results are shown in Table 5.

Step 3: obtain the weighted normalized matrix $\mathrm{Z}$ according to equation (11): 


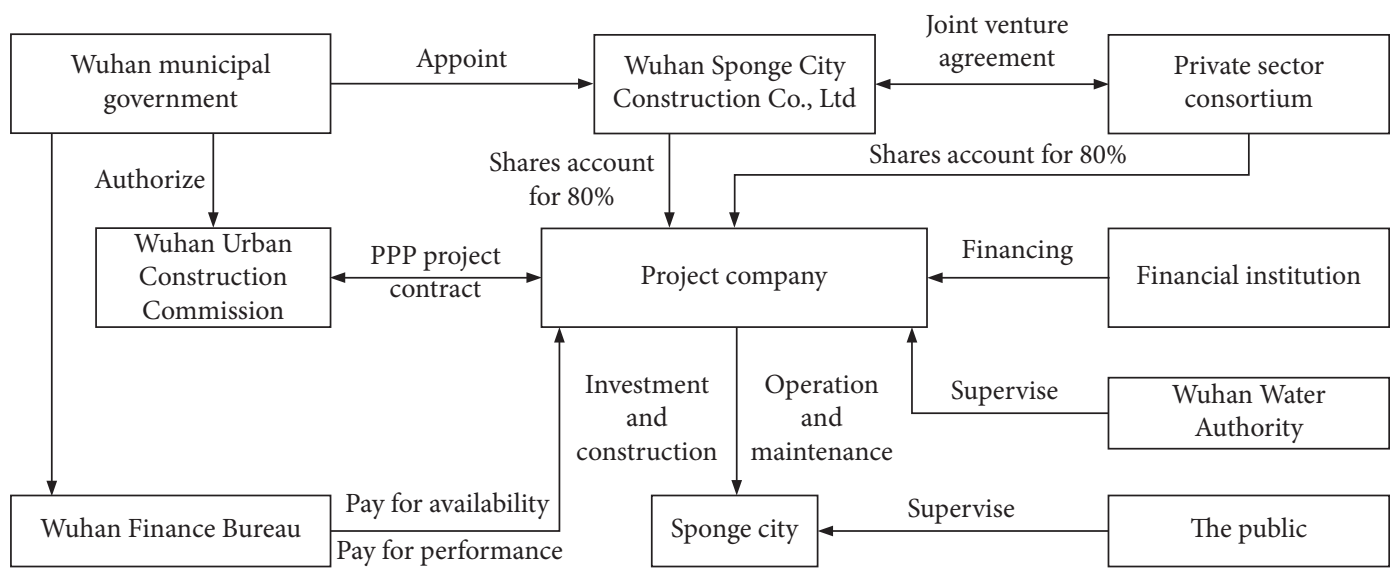

FIGURE 4: The specific operation mode of the case.

TABLE 4: Risk sensitivity.

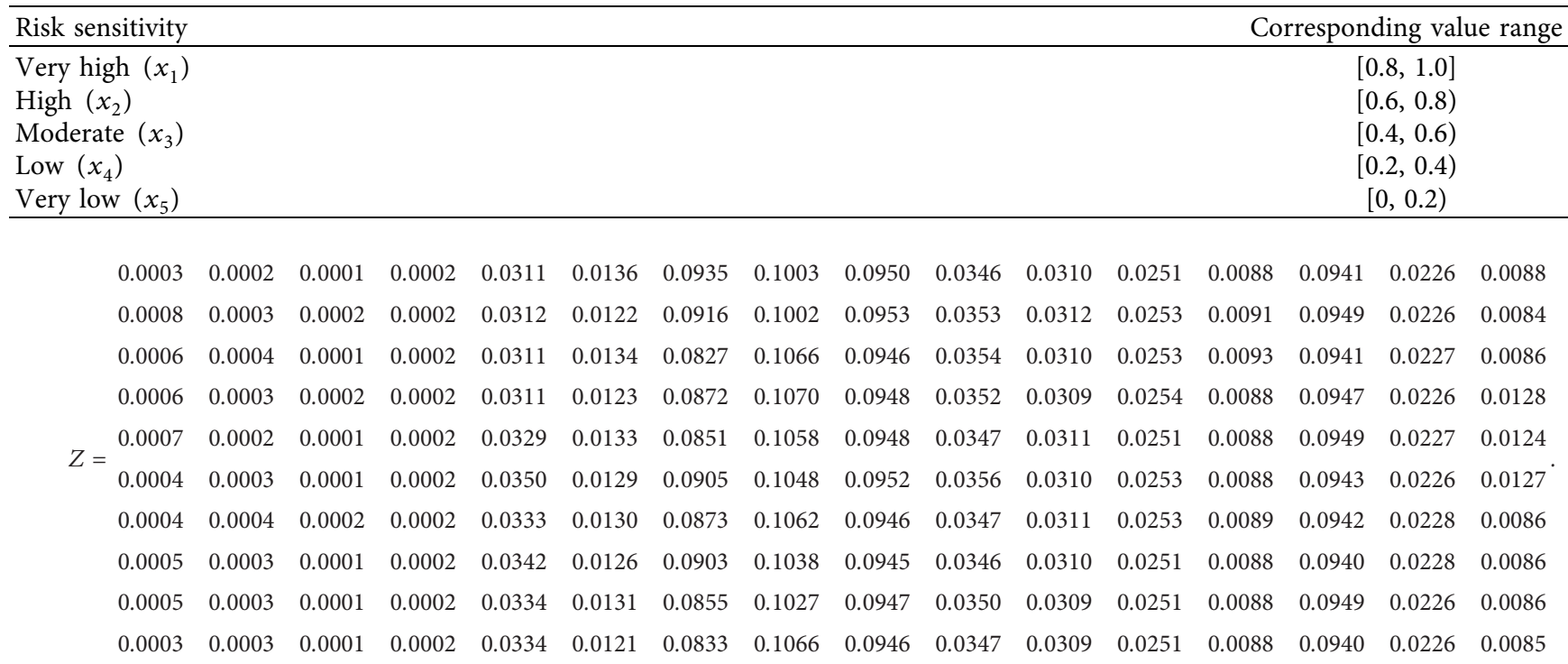

Step 4: determine positive ideal solutions $z_{j}^{+}$and negative ideal solutions $z_{j}^{-}$by equations (12) and (13):

$$
\begin{aligned}
& Z^{+}=(0,0,0,0,0,0,0,0,0,0,0,0,0,0,0,0) \\
& Z^{-}=(0.0126,0.0164,0.0102,0.0112,0.0395,0.0596,0.0434,0.0221,0.0498,0.0462,0.0361,0.0589,0.0336,0.0278,0.0792,0.0285)
\end{aligned}
$$

Step 5 : calculate the grey correlation $\gamma_{i}^{+}$and $\gamma_{i}^{-}$using equations (14)-(17):

$$
\begin{aligned}
& R^{+}=(0.0163,0.0167,0.0131,0.0128,0.3631,0.3781,0.3912,0.3101,0.9110,0.9101,0.9161,0.3166,0.1136,0.3152,0.4117,0.1010), \\
& R^{-}=(0.7301,0.6943,0.7131,0.6927,0.6871,0.6521,0.6161,0.6163,0.1323,0.1625,0.1612,0.6364,0.9124,0.6321,0.6312,0.7680)
\end{aligned}
$$


TABLE 5: Weights of $C_{1} \sim C_{16}$.

\begin{tabular}{|c|c|c|c|c|c|}
\hline First-level risk factors & Weight & Second-level risk factors & Subjective weight & Objective weight & Combination weight \\
\hline \multirow{4}{*}{$B_{1}$} & \multirow{4}{*}{0.219} & $c_{1}$ & 0.061 & 0.065 & 0.063 \\
\hline & & $c_{2}$ & 0.056 & 0.053 & 0.054 \\
\hline & & $c_{3}$ & 0.039 & 0.038 & 0.038 \\
\hline & & $c_{4}$ & 0.061 & 0.066 & 0.064 \\
\hline \multirow{3}{*}{$B_{2}$} & \multirow{3}{*}{0.182} & $c_{5}$ & 0.046 & 0.042 & 0.044 \\
\hline & & $c_{6}$ & 0.019 & 0.021 & 0.020 \\
\hline & & $c_{7}$ & 0.116 & 0.119 & 0.118 \\
\hline \multirow{5}{*}{$B_{3}$} & \multirow{5}{*}{0.340} & $c_{8}$ & 0.121 & 0.125 & 0.123 \\
\hline & & $c_{9}$ & 0.106 & 0.103 & 0.104 \\
\hline & & $c_{10}$ & 0.039 & 0.037 & 0.038 \\
\hline & & $c_{11}$ & 0.031 & 0.036 & 0.034 \\
\hline & & $c_{12}$ & 0.043 & 0.040 & 0.041 \\
\hline \multirow{4}{*}{$B_{4}$} & \multirow{4}{*}{0.259} & $c_{13}$ & 0.026 & 0.030 & 0.028 \\
\hline & & $c_{14}$ & 0.156 & 0.152 & 0.154 \\
\hline & & $c_{15}$ & 0.032 & 0.041 & 0.037 \\
\hline & & $c_{16}$ & 0.037 & 0.042 & 0.040 \\
\hline
\end{tabular}

TABLE 6: Initial risk sharing result.

\begin{tabular}{|c|c|c|}
\hline Risk-bearing type & Indicators of the risk & $\begin{array}{l}\text { Participant(s) bearing the } \\
\text { risk }\end{array}$ \\
\hline \multirow{3}{*}{$\begin{array}{l}\text { Risk taken } \\
\text { separately }\end{array}$} & Time delay $\left(c_{9}\right)$, lack of technical ability $\left(c_{10}\right)$, and change due to poor design $\left(c_{11}\right)$ & WGCCD \\
\hline & $\begin{array}{l}\text { Government intervention }\left(c_{1}\right) \text {, government default }\left(c_{2}\right) \text {, immature law and regulations } \\
\qquad\left(c_{3}\right) \text {, and government inaction }\left(c_{4}\right)\end{array}$ & WSCC \\
\hline & Lack of management experience $\left(c_{13}\right)$ and unreasonable operating technology $\left(c_{16}\right)$ & WCS \\
\hline \multirow{4}{*}{ Shared risk } & Project financing failure $\left(c_{5}\right)$ & WSCC, WIS, and FI \\
\hline & Interest rate $\left(c_{6}\right)$ and market price change $\left(c_{7}\right)$ & WIS and WCS \\
\hline & Cost overspending $\left(c_{8}\right)$ & WSCC, WGCCD, WIS, and \\
\hline & Insufficient operating income $\left(c_{14}\right)$ and lack of an effective payment mechanism $\left(c_{15}\right)$ & WSCC and WCS \\
\hline
\end{tabular}

Step 6: calculate the relative closeness value $R_{i}$ of WGCCD by equation (18):

$$
R=\frac{R^{+}}{R^{+}+R^{-}}=[0.022,0.023,0.018,0.018,0.346,0.367
$$$$
0.390,0.335,0.873,0.849,0.850,0.332,0.111,0.333 \text {, }
$$$$
0.395,0.116]
$$

In order to effectively define the sharing direction of risks, the interval estimation method is adopted here, which can not only deal with inaccurate judgment but also conveniently centralize different opinions and reduce the random error of expert judgment [42]. Based on the calculation process of the interval estimation method in [43], 10 experts take $[0,1]$ as the scoring interval. Finally, the following definition is finally obtained: if $R \geq 0.8$, the corresponding risk shall be borne by one participant alone; if $0.3 \leq R<0.8$, the corresponding risk should be shared by both participants (or multiple participants); and if $R<0.3$, the risk is not assumed.
Based on the above definition of the direction of risk sharing, the risks undertaken by WGCCD are as follows: (1) the risks to be undertaken alone include time delay $\left(c_{9}\right)$, lack of technical ability $\left(c_{10}\right)$, and change due to poor design $\left(c_{11}\right)$. (2) Risks to be shared with other participants include project financing failure $\left(c_{5}\right)$, interest rate $\left(c_{6}\right)$, market price change $\left(c_{7}\right)$, force majeure $\left(c_{12}\right)$, insufficient operating income $\left(c_{14}\right)$, and lack of an effective payment mechanism $\left(c_{15}\right)$. In the same way, we can get the risk exposure of other participants. As for the sponge city PPP project in Qingshan demonstration area of Wuhan city risk, after initial risk sharing, risk sharing of all participants is shown in Table 6.

4.2. Determine the Proportion of Shared Risks Based on the Utility Theory. Here, this paper takes four participants to jointly bear cost overspending $\left(c_{8}\right)$ as an example to discuss the problem of determining the proportion of a certain risk among four participants (WSCC, WGCCD, WIS, and WCS). From the view of this case, this situation is already the limit, and for this case where three participants share the risk or two participants share the risk, the calculation can be 
TABLE 7: The proportion of shared risks.

\begin{tabular}{lcc}
\hline Indicators of the risk & The proportion of the shared risk & Participant(s) bearing the risk \\
\hline Project financing failure $\left(c_{5}\right)$ & $0.378: 0.465: 0.157$ & WSCC, WIS, and FI \\
Interest rate $\left(c_{6}\right)$ & $0.645: 0.355$ & WIS and WCS \\
Market price change $\left(c_{7}\right)$ & $0.619: 0.381$ & WSCC, WGCCD, WIS, and WCS \\
Cost overspending $\left(c_{8}\right)$ & $0.163: 0.542: 0.1281: 0.167$ & WSCC and WCS \\
Insufficient operating income $\left(c_{14}\right)$ & $0.431: 0.569$ & Wack of an effective payment mechanism $\left(c_{15}\right)$
\end{tabular}

completed by removing one or two participants, respectively, from the established utility theory model.

Step 1: research hypothesis: in this example, it is assumed that WSCC, WGCCD, WIS, and WCS set the expected cost $C$ as 6 million yuan, 5 million yuan, 3 million yuan, and 2 million yuan, respectively.

Step 2: determine the utility functions of the four participants. As the initiator of the project, the representative of the government-WSCC, is often in the leading position in terms of contract signing and project negotiation, leading to differences in the weight coefficient of the four participants in the negotiation. The experts in Table 2 are consulted, and the AHP is used to determine the weights of WSCC, WGCCD, WIS, and WCS which are $0.4,0.3,0.2$, and 0.1 , respectively. Based on the simulation, the utility function of the four participants against the cost overspending $\left(c_{8}\right)$ risk can be expressed:

$$
\left\{\begin{array}{l}
U_{1}=U_{1}\left(V_{1}, C_{1}\right)=\left(\frac{-1}{450}\right) C_{1}^{2}+V_{1}+1, \\
U_{2}=U_{2}\left(V_{2}, C_{2}\right)=\left(\frac{-1}{320}\right) C_{2}^{2}+V_{2}+1, \\
U_{3}=U_{3}\left(V_{3}, C_{3}\right)=\left(\frac{-1}{240}\right) C_{3}^{2}+V_{3}+1, \\
U_{4}=U_{4}\left(V_{4}, C_{4}\right)=\left(\frac{-1}{160}\right) C_{4}^{2}+V_{4}+1 .
\end{array}\right.
$$

Step 3: determine the proportion of shared risks. Set the initial utility values of the above four participants as $U_{1}^{\prime}=U_{2}^{\prime}=U_{3}^{\prime}=U_{4}^{\prime}$. Then, expectation cost of the cost overspending $\left(c_{8}\right)$ risk is $C_{r}=C_{e l}+C_{c 2}+C_{e 3}+C_{e 4} / 4=400$ by using equation (28). Putting the utility function and the weight values of the three participants into equation (25), we can get

$$
\max f\left(U_{1}, U_{2}, U_{3}, U_{4}\right)=\max F\left(t_{1}^{\prime}, t_{2}^{\prime}, t_{3}^{\prime}\right) \text {. }
$$

Make $\partial F / \partial t_{1}^{\prime}=0, \partial F / \partial t_{2}^{\prime}=0$, and $\partial F / \partial t_{3}^{\prime}=0$; we can obtain $t_{1}^{\prime}=0.163, t_{2}^{\prime}=0.542, t_{3}^{\prime}=0.128$, and $t_{4}^{\prime}=0.167$. Optimal sharing proportion of WSCC, WGCCD, WIS, and WCS with respective cost overspending (c8) is $0.163: 0.542$ : $0.1281: 0.167$. Similarly, the optimal sharing proportion of other co-risk factors can be calculated, as shown in Table 7.
Through comparative analysis with the practical situation of the sponge city PPP project in Qingshan demonstration area of Wuhan city, it is found that, after the risk sharing is carried out using this risk-sharing framework, its risk factor sharing is consistent with the risk sharing stipulated in the contract, which verifies that this risk-sharing framework has good feasibility and effectiveness. At the same time, the risk-sharing framework also gives the specific sharing proportion for the shared risks, but the sharing proportion is not given in the contract. It can be seen that the risk-sharing framework is more perfect and detailed than the provisions in the contract.

\section{Conclusion}

Construction of sponge city projects can effectively solve a series of problems such as rainwater flooding, surface runoff, and water pollution and is considered as an effective way to achieve the sustainable urbanization. The sponge city project chooses the PPP financing mode with obvious advantages to make up for the huge investment gap. To assure success of sponge city PPP projects, the risks must be reasonably shared among participants. To solve this problem, from the perspective of the individual participant, this paper constructs a risk-sharing framework for sponge city PPP projects, which could not only enable each participant to obtain the risk he should bear independently but also obtain the proportion of the risk they should bear together, thus realizing the reasonable risk sharing among participants. This paper mainly achieves the following research: (1) in existing PPP project risk research, participants are mostly divided into public sector and private sector, which makes it difficult for the individual participant to grasp his own risk state. This paper solves this problem from the perspective of the individual participant. (2) At present, the risk evaluation index system of sponge city PPP projects is still not perfect. In view of this deficiency, this paper combines the actual situation of sponge city PPP projects and constructs a perfect evaluation index system by using the Delphi method. The final risk evaluation index system is established from the perspectives of political risks, economic risks, construction risks, and operational risks, which include 16 secondary risk factors. (3) In determining the weight of each risk index of sponge city PPP projects, the single method (subjective weight method or objective weight method) is still the main method at present. In order to make the weight of the risk index more reasonable, this paper adopts the combined weight method (combining the G1 method and the C-OWA operator). (4) The previous PPP project risk studies are basically conducted by 
viewing participants as a whole or dividing them into the government sector and private sector. If an individual participant wants to obtain the risk status he bears, the existing risk-sharing methods cannot realize this demand. To solve this problem, this paper proposes a feasible risk-sharing method and completes the individual participant's demand in two steps. (1) Realize the initial sharing of risks using the GCA method and TOPSIS method to solve the risks that can be taken by one participant and define the risks that need to be shared. (2) Determine the proportion of risks shared by both or more participants based on the utility theory. Risk sharing of sponge city PPP projects is the focus of the current research and attracts much attention from researchers. As a core part of sponge city PPP projects' risk management, risk sharing of sponge city PPP projects plays an important role though few studies have carried out careful identification of their critical risk factors and reasonably risk sharing. This paper attempted to contribute to this section.

This study also has limitations and shortcomings. Due to inadequate experience in sponge city PPP projects, the risk evaluation index system cannot be perfect. The availability of collected risk data should be more accurate and feasible. In the next study, identification methods of risk factors can be innovated. Additionally, in this risk-sharing framework, some quantitative methods are proposed, such as the weight determination method, risk initial sharing method, and risk proportion determination method. If other new risk-sharing methods appear, the comparative study of risk-sharing methods can be carried out next.

\section{Data Availability}

The data used to support the findings of this study are available from the project library of China Public Private Partnerships Center (CPPPC).

\section{Conflicts of Interest}

The authors declare that there are no conflicts of interest regarding the publication of this paper.

\section{Acknowledgments}

The authors would like to extend their gratitude to the 10 experts for questionnaire respondents for valuable contributions to this research project. They also thank the National Natural Science Foundation of China (Grant no. 71471094).

\section{References}

[1] T. T. Nguyen and H. H. Ngo, "Implementation of a specific urban water management-Sponge city," Science of the Total Environment, vol. 652, pp. 147-162, 2019.

[2] D. R. Marlow, M. Moglia, S. Cook, and D. J. Beale, “Towards sustainable urban water management: a critical reassessment," Water Research, vol. 47, no. 20, pp. 7150-7161, 2013.

[3] H. Li, L. Ding, M. Ren, C. Li, and H. Wang, "Sponge city construction in China: a survey of the challenges and opportunities," Water, vol. 9, no. 9, p. 594, 2017.

[4] Y. Jiang, C. Zevenbergen, and Y. Ma, "Urban pluvial flooding and stormwater management: a contemporary review of
China's challenges and "Sponge cities" strategy," Environmental Science \& Policy, vol. 80, pp. 132-143, 2018.

[5] Y. Wu, C. Xu, L. Li, Y. Wang, K. Chen, and R. Xu, “A risk assessment framework of PPP waste-to-energy incineration projects in China under 2-dimension linguistic environment," Journal of Cleaner Production, vol. 183, pp. 602-617, 2018.

[6] Z. Wu, H. Li, Y. Feng, X. Luo, and Q. Chen, "Developing a green building evaluation standard for interior decoration: a case study of China," Building and Environment, vol. 152, pp. 50-58, 2019.

[7] B. Li, A. Akintoye, and P. J. Edwards, "Perceptions of positive and negative factors influencing the attractiveness of PPP/PFI procurement for construction projects in the UK: findings from a questionnaire survey," Finite Elements in Analysis \& Design, vol. 68, no. 2, pp. 1-9, 2013.

[8] A. P. C. Chan, J. F. Y. Yeung, C. C. P. Yu, S. Q. Wang, and Y. Ke, "Empirical study of risk assessment and allocation of public-private partnership projects in China," Journal of Management in Engineering, vol. 27, no. 3, pp. 136-148, 2011.

[9] D. Wang, "Uncertainty, risk aversion, and the game theoretic foundations, of the safe minimum standard: a reassessment," Ecological Economics, vol. 29, pp. 463-472, 2011.

[10] F. Medda, "A game theory approach for the allocation of risks in transport pubic private partnerships," International Journal of Project Management, vol. 25, pp. 231-218, 2017.

[11] J. Song and L. Chen, "Research on risk sharing of PPP plus EPC sewage treatment project based on bargaining game mode," Presenius Environmental Bulletin, vol. 29, no. 2, pp. 903-912, 2020.

[12] L. Zhang and W. Zhang, "A case study of water conservation evaluate for green building," Advanced Materials Research, vol. 374-377, pp. 62-65, 2012.

[13] D. A. Kening, J. I. Ying, Z. Shiqi et al., "Research on strategies against PPP financing mode for sponge city construction," Journal of Shenyang Jianzhu University, vol. 36, pp. 45-50, 2016.

[14] Y. Wang, M. Sun, and B. Song, "Public perceptions of and willingness to pay for sponge city initiatives in China," Resources, Conservation and Recycling, vol. 122, pp. 11-20, 2017.

[15] H. Li, L. Ding, C. Li, and H. Wang, "Sponge city construction in China: a survey of the challenges and opportunities," Water, vol. 9, no. 9, p. 594, 2017.

[16] L. Wang, X. Sun, and H. Xue, "Identifying critical risks in Sponge city PPP projects using DEMATEL method: a case study of China," Journal of Cleaner. Production, vol. 226, pp. 945-958, 2019.

[17] K. C. Lam, D. Wang, P. T. K. Lee, and Y. T. Tsang, "Modelling risk allocation decision in construction contracts," International Journal of Project Management, vol. 25, no. 5, pp. 485-493, 2007.

[18] Y. J. Tsang, "Preferred risk allocation in China's public-private partnership (PPP) projects," International Journal of Project Management, vol. 8, pp. 1-11, 2009.

[19] X. H. Jin, “A neuro-fuzzy decision support system for efficient risk allocation in public-private partnership infrastructure projects," Journal of Computing in Civil Engineering, vol. 4, pp. 223-235, 2013.

[20] B. Li and Z. M. Ren, "Bayesian technique framework for allocating demand risk between the pubic and private sector in PPP projects," in Proceedings of the 6th International Conference on Service Systems and Service Management, pp. 837-841, Corsica, France, September 2015.

[21] E. E. Ameyaw and A. P. C. Chan, "A fuzzy approach for the allocation of risks in public-private partnership water- 
Infrastructure projects in Developing Countries," Journal of Infrastructure Systems, vol. 22, no. 3, pp. 1-10, 2016.

[22] Z. Li and M. Liu, "Study on allocation proportion model of PPP project financing risk based on utility theory," Journal of System Science, vol. 26, no. 1, pp. 111-114, 2018.

[23] J. Y. Song and E. S. Chung, "A multi-criteria decision analysis system for prioritizing sites and types of low impact development practices: case of Korea," Water, vol. 4, no. 9, pp. 1-17, 2017.

[24] A. Shrestha, J. Tamošaitienè, I. Martek, M. R. Hosseini, and D. J. Edwards, "A principal-agent theory perspective on PPP risk allocation,” Sustainability, vol. 11, no. 22, p. 6455, 2019.

[25] H. W. Martek, J. J. Ruan, and F. Li, "A fuzzy evaluation and AHP based method for the energy efficiency evaluation of EV charging station," Journal of Computer, vol. 9, pp. 1185-1192, 2014.

[26] R. Osei-Kyei and A. P. C. Chan, "Review of studies on the critical success factors for public-private partnership (PPP) projects from 1990 to 2013," International Journal of Project Management, vol. 33, no. 6, pp. 1335-1346, 2015.

[27] Y. Ke, S. Wang, A. P. C. Chan, and P. T. I. Lam, "Preferred risk allocation in China's public-private partnership (PPP) projects," International Journal of Project Management, vol. 28, no. 5, pp. 482-492, 2010.

[28] Q. Lang, D. Xu, and L. Li, "Study on risk sharing mechanism of Sponge city PPP project," Management and Administration, vol. 11, pp. 141-144, 2017.

[29] S. Wang and H. Shengyue, "A risk dynamic evaluation of PPP projects in sponge city based on system dynamics," Journal of Engineering Management, vol. 33, no. 3, pp. 63-68, 2019.

[30] J. R. Vogel, T. Moore, R. Coffman, and S. Rodie, "Critical review of technical questions facing low impact development and green infrastructure: a perspective from the great plains: a perspective from the great plains," Water Environment Research, vol. 87, no. 9, pp. 849-862, 2015.

[31] Y. McDonough, A. P. C. Chan, B. Xia, Q. K. Qian, Y. Liu, and Y. Peng, "Critical risk factors affecting the implementation of PPP waste-to-energy projects in China," Applied Energy, vol. 158, pp. 403-411, 2015.

[32] L. Kumar, A. Jindal, and N. R. Velaga, "Financial risk assessment and modelling of PPP based Indian highway infrastructure projects," Transport Policy, vol. 62, pp. 2-11, 2018.

[33] J. Xia, Y. Zhang, L. Xiong, S. He, L. Wang, and Z. Yu, "Opportunities and challenges of the Sponge City construction related to urban water issues in China," Science China Earth Sciences, vol. 60, no. 4, pp. 652-658, 2017.

[34] J. Olorunkiya, E. Fassmen, and S. Wilkinson, "Risk: a fundamental barrier to the implementation of low impact design infrastructure for urban storm water control," Journal of Sustainable Development, vol. 5, no. 9, pp. 27-41, 2012.

[35] A. Shrestha, T.-K. Chan, A. A. Aibinu, and C. Chen, "Efficient risk transfer in PPP wastewater treatment projects," Utilities Policy, vol. 48, pp. 132-140, 2017.

[36] A. Benzerra, M. Cherrared, B. Chocat, F. Cherqui, and T. Zekiouk, "Decision support for sustainable urban drainage system management: a case study of Jijel, Algeria: a case study of Jijel, Algeria," Journal of Environmental Management, vol. 101, no. 101, pp. 46-53, 2012.

[37] B. Cherqui and Y. Hu, "Critical factors of effective public participation in sustainable energy projects," Journal of Management in Engineering, vol. 24, no. 5, pp. 1-12, 2019.

[38] H. Zhao, Z. Bu, and S. Ma, "Risk evaluation of sewage treatment PPPABS projects using combination weight method and D-S evidence theory," Complexity, vol. 2020, Article ID 4167130, 12 pages, 2020.

[39] R. R. Yager, "Families of OWA operators," Fuzzy Sets and Systems, vol. 59, pp. 125-148, 1993.

[40] F. Y. Meng, J. Tang, S. L. Zhang, and Y. W. Xu, "Public-private partnership decision making based on correlation coefficients of single-valued neutrosophic hesitant fuzzy sets," Informatica, vol. 31, no. 2, pp. 359-397, 2020.

[41] J. Liu and Q. Wei, "Risk evaluation of electric vehicle charging infrastructure public-private partnership projects in China using fuzzy TOPSIS," Journal of Cleaner Production, vol. 189, pp. 211-222, 2018.

[42] W. Zhou, "Study on risk allocation of Spongy city project under the model of public-private partnership," pp. 52-54, Shenzhen University, Shenzhen, China, 2018, Master thesis.

[43] X. Wang, H. Zhao, and G. Yu, "Construction of progress deviation monitoring system for key construction projects in Tianjin Binhai new area," Statistics and Decision, vol. 2, pp. $48-50,2008$. 